\title{
Ghrelin Receptor Is Required for the Effect of Nesfatin-1 on Glucose Metabolism
}

\author{
Xin-Tong Fan ${ }^{1 \dagger}$, Zhao Tian ${ }^{1+}$, Shi-Zhen $\mathrm{Li}^{2+}$, Ting Zhai ${ }^{2+}$, Jun-Li Liu ${ }^{3}$, Rui Wang ${ }^{4}$, \\ Cai-Shun Zhang ${ }^{4}$, Liu-Xin Wang ${ }^{4}$, Jun-Hua Yuan ${ }^{4}$, Yu Zhou ${ }^{5}$ and Jing Dong ${ }^{4,5 *}$ \\ ${ }^{1}$ Clinical Medicine Department, Medical College, Qingdao University, Qingdao, China, ${ }^{2}$ Preventive Medicine Department, \\ School of Public Health, Qingdao University, Qingdao, China, ${ }^{3}$ Fraser Laboratories for Diabetes Research, Department of \\ Medicine, The Research Institute of McGill University Health Centre, Montreal, QC, Canada, ${ }^{4}$ Special Medicine Department, \\ Medical College, Qingdao University, Qingdao, China, ${ }^{5}$ Physiology Department, Medical College, Qingdao University, \\ Qingdao, China
}

Studies of nesfatin-1 in glucose metabolism have become a topic of interest recently, however, the specific receptor for nesfatin-1 has not yet been identified. Some studies hinted at a connection between nesfatin-1 and the ghrelin receptor, growth hormone secretagogue receptor. Therefore, we aimed to study the role of GHSR in the glycemic effects of nesfatin-1 as well as its downstream pathways. We employed C57/BL6 mice (wild type and GHSR knockout mice) eating a normal chow diet and a high fat diet in this study, and the experimental technique included western blot, real-time PCR, immunofluorescence and ELISA. We found that in mice fed a normal chow diet (NCD), nesfatin-1 improved glucose tolerance, up-regulated AKT kinase (AKT) mRNA levels and phosphorylation and GLUT4 membrane translocation in skeletal muscle. These effects were blocked by co-injection of GHSR antagonist [D-Lys3]-GHRP-6 and were attenuated in GHSR knockout mice. In mice fed high-fat diet (HFD), nesfatin-1 not only exerted the effects observed in NCD mice, but also suppressed appetite and raised AKT levels in liver tissues that also required GHSR. Peripheral nesfatin-1 suppressed c-fos expression of GHSR immunoreactive neurons induced by fasting in hypothalamic nuclei, indicating that nesfatin-1 inhibited the activation of central GHSR. We concluded that the effects of nesfatin-1 on food intake and glucose metabolism were GHSR-dependent, and that the glycemic effect was associated with AKT and GLUT4. This study should stimulate further exploration of the nesfatin-1 receptor.

Keywords: nesfatin-1, ghrelin receptor, glucose metabolism, AKT, high fat diet

\section{INTRODUCTION}

Nesfatin-1 is an anorexic peptide discovered in 2006 (1). Protein nucleobindin-2 (NUCB2), its precursor, was found to be related to severe obesity in human children (2). Nesfatin1 immunoreactive cells are distributed in central neurons (3-5) and some peripheral tissues, including gastric mucosa, heart, islet cells, and adipose tissue (6-10). It has been shown to inhibit food intake and reduce body weight both centrally $(1,11)$ and peripherally $(12)$, suggesting a potential therapeutic role in obesity. 
Nesfatin-1 also participates in regulation of blood glucose. Continuous subcutaneous administration of nesfatin-1 diminishes blood glucose levels during the oral glucose tolerance test (OGTT), while intracerebroventricular (ICV) injection of nesfatin-1 did not reduce blood glucose levels (13), suggesting that the glycemic effect of nesfatin-1 may be peripheral. Another study found that the effect of peripheral nesfatin-1 on reducing blood glucose was mediated in a glucose- and insulin-dependent manner (14). In addition, nesfatin-1 decreased blood glucose indirectly in other organs: co-injection of insulin and nesfatin-1 increased phosphorylation levels of AKT kinase (AKT) in liver, skeletal muscle, and adipose tissue, and thus improved GLUT4 levels to increase glucose uptake (13).

Ghrelin, purified from rat stomach in 1999 by Kojima et al. (15), has also emerged as a pivotal player in the regulation of appetite and energy metabolism. Both central and peripheral injection of ghrelin increased appetite and body weight $(16,17)$. Studies have found that ghrelin promoted the synthesis of liver glycogen (18), increased blood glucose, and inhibited insulin release (19), all of which underscore the important effect of ghrelin in modulating glucose metabolism. Growth hormone secretagogue receptor (GHSR), considered the main receptor for ghrelin (20), was found to be expressed in pancreatic $\beta$-cells (2123), and insulin levels decreased in GHSR knockout mice (24). This suggested a critical role for GHSR in regulating glucose homeostasis. More importantly, a study illustrated that GHSR had high constitutive activity independent of ghrelin (25). This implied that ligand-independent signaling can be affected by other unidentified inverse agonist, to exert the corresponding functions.

Together, nesfatin-1 and ghrelin both play a profound part in regulating the energy state. Interestingly, nesfatin-1 and ghrelin were both secreted by X/A-like cells and co-localized in gut and brain $(26,27)$. Kerbel et al. employed goldfish to study the relationship between the two brain-gut peptides and found that nesfatin-1 injection changed the expression of ghrelin and its active receptor GHSR 1a-1 (26). Another study suggested that nesfatin-1 interacted with the G-protein-coupled receptors in mouse brain (3). Interestingly, GHSR was also shown to be a $\mathrm{G}$ protein-coupled receptor (28). Furthermore, nesfatin-1 and GHSR co-exist in human pancreatic beta cells (29), while there is no ghrelin in human beta cells (30). In addition, GHSR and nesfatin-1 in beta cells were closely related to the regulation of insulin secretion (31-33). Based on all these observations, because the nesfatin-1 receptor has not been identified, we hypothesized that nesfatin-1 may have a direct or indirect effect on GHSR when modulating glucose metabolism. Based on the results we obtained, we confirmed our hypothesis that nesfatin1 modulated satiety, and that glucose metabolism mediated by GHSR at least partly requires its participation.

\section{MATERIALS AND METHODS}

\section{Animals}

Adult male wild-type (GHSR ${ }^{+/+}$) and GHSR-null (GHSR ${ }^{-/-}$) mice (age 8 weeks) (34) on a C57BL/6J background, were housed in standard rodent cage. The original $\mathrm{GHSR}^{-/-}$mice were purchased from Shanghai Research Center For Model Organisms Of China, and the GHSR ${ }^{-/-}$mice were obtained from crosses between heterozygous and homozygous knockout animals that were backcrossed over 10 generations (35). The environment conditions were controlled $\left(23 \pm 2{ }^{\circ} \mathrm{C}\right.$, illumination from 0700 to $1900 \mathrm{~h}$ ). Food and water were available ad libitum, except during the specified experiments. The experimental protocols were approved by the Qingdao University Animal Care and Use Committee and Animal Welfare Committee in accordance with the National Institutes of Health guidelines.

\section{Experimental Procedures}

Eight-week-old mice were allowed free access to standard laboratory normal chow diet (NCD, $10 \%$ calories from fat: $51.5 \%$ wheat, $20 \%$ fat-free milk, $11.25 \%$ soybean meal, $10.25 \%$ vegetable oil, $4 \%$ bear yeast, $1.375 \%$ salt, $0.125 \%$ ferric citrate, $0.5 \%$ vitamins, $1 \%$ calcium hydrophosphate. Qingdao Daren Fortune Animal Technology) or high-fat diet (HFD, $60 \%$ calories from fat: $59 \%$ basic mice feed, $20 \%$ sugar, $18 \%$ lard, and 3\% egg yolk) for 8 weeks. Before the experimental procedures, mice were housed individually and habituated to the irritation of intravenous administration.

\section{Experimental Groups}

A. GHSR ${ }^{+/+}$mice fed NCD were randomly divided into four groups according to a random number table. Vehicle (normal saline, $n=6$ ) or nesfatin-1 (100 pmol/mouse/day, 1-82; Phoenix Pharmaceuticals, Burlingame, CA, USA, $n=6$ ) or [D-Lys3]-GHRP-6 (GHSR antagonist, $16.7 \mu \mathrm{g} / \mathrm{mouse} /$ day; ApexBio, Houston, USA, $n=6$ ) or co-injection of nesfatin- 1 and [D-Lys3]-GHRP-6 $(n=8)$ was injected into the tail vein daily for 12 days (13). Nesfatin-1 and [D-Lys3]-GHRP-6 were premixed into one solution before the co-injection of the two drugs. $\mathrm{B}$. $\mathrm{GHSR}^{+/+}$mice fed HFD were randomly divided into two groups. Vehicle $(n=6)$ or nesfatin-1 $(n=6)$ was injected into the tail vein daily for 12 days. C. GHSR ${ }^{-/-}$mice fed NCD and HFD were randomly divided into two groups (vehicle and nesfatin-1), respectively (NCD, vehicle: $n=3$; NCD, nesfatin-1: $n=4$; HFD, vehicle: $n=5$; HFD, nesfatin-1: $n=5$ ). Drugs were injected daily for 12 days.

\section{Experimental Procedures}

Administrations were conducted in the evening at $1800 \mathrm{~h}$ before the onset of the dark cycle (day 1-11) in mice fasting for $6 \mathrm{~h}$ (except OGTT), with the last injection at $0900 \mathrm{~h}$ in the morning (day 12) after mice fasted for $12 \mathrm{~h}$. When indicated, wildtype mice and GHSR knockout mice underwent treatment with intraperitoneal insulin (2 U/kg body weight; Wan Bang, China) $10 \mathrm{~min}$ before sacrifice, since the effect of peripheral nesfatin1 on regulating AKT and GLUT4 was insulin-dependent (13). Mice were sacrificed $1.5 \mathrm{~h}$ after the last administration of vehicle, nesfatin-1, GHSR antagonist or the co-injection of nesfatin1 and GHSR antagonist. Skeletal muscle and liver tissue were harvested, temporarily placed in liquid nitrogen, and promptly transferred to $\mathrm{a}-80^{\circ} \mathrm{C}$ freezer (Thermo Scientific ${ }^{\mathrm{TM}}$ ) until they were assayed for AKT phosphorylation (p-AKT/AKT), GLUT4 protein expression levels, and mRNA levels of AKT and GLUT4. 
The inclusion and exclusion of data were based on the accuracy of experimental procedures and surgeries. All experimenters were blind to group assignment and outcome assessment. To reduce experimental error, we conducted several measurements for each sample and every substantial deviation from normal value was repeated to improve the accuracy of the experiment.

\section{Food Intake}

Food intake was detected during the 12-day administration mentioned above. Food was returned to the mice immediately after tail vein administration and was measured by electronic precision scales (Feeding and Activity Analyzer, Ugo Basile, Italy) at $0.5,1,2,3$, and $12 \mathrm{~h}$ after injection.

\section{Body Weight and Glucose Measurement}

Body weight (initial weights: 18-22 gram) was measured on a weekly basis during high fat diet (HFD) with an electric balance (Mettler Toledo, PL1501-S, Shanghai, China). For the effect of nesfatin-1 modulating acute blood glucose (BG), we measured BG using tail vein prick and a glucometer (B, Braun, Meisungen AG, Germany) before administration, and at 1 and $3 \mathrm{~h}$ after the injection during the 12-day administration period. For the effect of nesfatin-1 regulating chronic BG, we measured BG at the beginning and the end of the 12-day administration (before mice were sacrificed).

\section{Oral Glucose Tolerance Test (OGTT)}

OGTT was performed on day 8 during the 12-day administration period. The mice were fasted for $16 \mathrm{~h}$ before OGTT (36) and were then injected with vehicle or nesfatin-1, after which they were immediately treated with glucose ( $3 \mathrm{~g} / \mathrm{kg}$ body weight) orally. Blood glucose concentration was measured at $0,15,30$, 60,120 min after gavage, using the glucometer described above.

\section{Biochemical Analysis}

Blood was sampled from the tip of the tails of $\mathrm{GHSR}^{+/+}$and $\mathrm{GHSR}^{-/-}$mice that had been fed ad libitum or fasted for $12 \mathrm{~h}$. Plasma was immediately transferred into EP tubes to determine the levels of nesfatin-1. Plasma nesfatin-1 was measured by ELISA (Cloud-Clone Crop, USA, CEA242Mu).

\section{Real-Time PCR}

TRIzol reagent (Vazyme Biotech Co., Ltd, China) was used to isolate total RNA from liver and skeletal muscle. By measuring absorbance at $260 \mathrm{~nm}$, we quantified the RNA concentration and used the ratio of absorbance at 260 and $280 \mathrm{~nm}$ in a spectrophotometer to assess the purity of RNA. RNA was then reverse transcribed into cDNA using HiScript II Q RT SuperMix for qPCR (Vazyme Biotech Co., Ltd, China). The obtained cDNA was used to determine the mRNA levels of AKT and GLUT4 (skeletal muscle, liver) by real-time PCR using ChamQ SYBR qPCR Master Mix (Vazyme Biotech Co., Ltd, China). The primer sequences (designed by Shanghai Sangon, China) are shown in Table 1. Amplification was initiated at $95^{\circ} \mathrm{C}$ for $10 \mathrm{~min}$, followed by 35 cycles at $95^{\circ} \mathrm{C}$ for $10 \mathrm{~s}$, and then at $60^{\circ} \mathrm{C}$ for $30 \mathrm{~s}$ and finally terminated at $72^{\circ} \mathrm{C}$ for $30 \mathrm{~s}$. The relative expression levels of AKT and GLUT4 were normalized to $\beta$-actin threshold cycle (Ct) values, and the fold changes of each target gene were calculated using the $2(-\Delta \Delta \mathrm{Ct})$ method.

\section{Western Blot}

We extracted proteins from liver, skeletal muscle with RIPA Lysis Buffer (Beyotime, P0013B, China). Proteins were denatured in SDS sample buffer $\left(95^{\circ} \mathrm{C}, 5 \mathrm{~min}\right)$ and then were subjected to $12 \%$ SDS-PAGE.

Proteins were then transferred on a polyvinylidene fluoride membranes (Millipore Corp., Billerica, MA, USA) for $2 \mathrm{~h}$. Blocking was performed, and membranes were incubated overnight $\left(4^{\circ} \mathrm{C}\right)$ in primary antibodies (p-AKT: rabbit IgG, 1:2000, Cell Signaling Technology, PSER473, \#4060, USA; AKT: rabbit IgG, 1:2,000, Sigma, SAB4500797, Germany; GLUT4: rabbit IgG, 1:2,000, Abcam, ab33780, US; $\beta$-actin: rabbit IgG, 1:2,000, Cell Signaling Technology, D6A8, \#8457, USA). Secondary antibodies (Goat Anti-rabbit IgG, 1:8,000, Boaosen, bs-0295G-HRP, China) were incubated on the membranes for $1 \mathrm{~h}$ at room temperature. Detection of proteins was performed with an enhanced chemiluminescence reagent (Millipore, WBKLS0100, USA). Image J was used for intensity analysis.

\section{Immunofluorescence}

All mice used for immunofluorescence were fasted for $12 \mathrm{~h}$ before IV treatment (37). C57/BL6 mice had access to free time for $90 \mathrm{~min}$ after tail vein injection with nesfatin-1(100 pmol/mouse, 1-82; Phoenix Pharmaceuticals, Burlingame, CA, USA, $n=3)$ or vehicle $(n=3)$, and after this period, the mice were deeply anesthetized with chloral hydrate, then quickly perfused transcardially with $30 \mathrm{ml} 0.1 \mathrm{M}$ PBS, followed by $30 \mathrm{ml} 4 \%$ paraformaldehyde in $0.1 \mathrm{M}$ PBS. The brains were quickly removed immediately following perfusion and were post-fixed in $4 \%$ paraformaldehyde overnight at $4^{\circ} \mathrm{C}$. After post-fixation, the brains were transferred to $20 \%$ sucrose solutions for $12 \mathrm{~h}$, then were moved to $30 \%$ sucrose solution for another $12 \mathrm{~h}$. The brains were sectioned at $15 \mu \mathrm{m}$ on a freezing microtome (Kryostat 1,720; Leica, Germany), and sections were placed on glass slides. Then sections were soaked in $0.01 \mathrm{M}$ PBS for $15 \mathrm{~min}$, followed by antigen retrieval in a microwave oven. Then sections were washed in $0.01 \mathrm{M}$ PBS three times ( $7 \mathrm{~min}$ per wash). After washing, sections were blocked for $2 \mathrm{~h}$ at room temperature in $0.01 \mathrm{M}$ PBS buffer with $1 \%$ BSA containing $0.1 \%$ Triton-X, then incubated overnight at $4{ }^{\circ} \mathrm{C}$ in primary antibody against c-fos (sheep antic-fos polyclonal antibody, 1:200, Millipore) diluted in blocking solution. Following three washes in $0.01 \mathrm{M}$ PBS, sections were incubated with secondary antibody (donkey anti-sheep, red, $1: 200, \mathrm{R} \& \mathrm{D})$ diluted in PBS for $2 \mathrm{~h}$ at room temperature. Then they were mounted with coverslips with $50 \%$ glycerol after three PBS washes.

For the evaluation of GLUT4 membrane translocation, muscle tissues were harvested $90 \mathrm{~min}$ after tail vein injection with nesfatin-1 (100 pmol/mouse) or vehicle in $\mathrm{GHSR}^{+/+}$ and $\mathrm{GHSR}^{-/-}$mice fasted for $12 \mathrm{~h}$, with intraperitoneal insulin (2 U/kg body weight) $10 \mathrm{~min}$ before sacrifice $(n=$ 
TABLE 1 | Premier sequences for real-time PCR.

\begin{tabular}{|c|c|c|}
\hline Gene & Forward & Reverse \\
\hline AKT serine/threonine kinase 1 (AKT1) & 5'-AGATTGTGTCGCCCGGAC-3' & 5'-AGCCCGAAGTCCGTTATCTT-3' \\
\hline Solute carrier family 2 member 4 (GLUT4) & 5'-TCTTATTGCAGCGCCTGAGTC-3' & 5'-GCCAAGCACAGCTGAGAATACA-3' \\
\hline Actin beta ( $\beta$-actin) & 5'-CCACTGCCGCATCCTCTTCC-3' & 5'-CTCGTTGCCAATAGTGATGAC-3' \\
\hline
\end{tabular}

3/group). After perfusion described above, muscle was postfixed in $70,80,90,100,100 \%$ paraformaldehyde for $30 \mathrm{~min}$, respectively. Then muscle was transferred into dimethylbenzene for $4 \mathrm{~min}$, following immersion in soft wax, hard wax, and mixed waxes for $40 \mathrm{~min}$, respectively. After sectioning, sections were placed in 100, 100, 90, 80, 70\% alcohol solution for $5 \mathrm{~min}$, respectively, followed by dimethylbenzene dewaxing for $20 \mathrm{~min}$. After washing in $0.01 \mathrm{M}$ PBS, the following immunostaining protocols were as described above. Blocking buffer: 1\% BSA in 0.01M PBS. Primary antibody: Rabbit Anti-Glucose Transporter GLUT4 polyclonal antibody (1:100, ab654, Abcam), incubated overnight at $4^{\circ} \mathrm{C}$; Second antibody: Fluorescein-Conjugated AffiniPure Goat Anti-Rabbit IgG $(\mathrm{H}+\mathrm{L})$ (1:300, ZSGB-BIO), incubated for $2 \mathrm{~h}$ at room temperature.

A confocal scanning laser microscope (FV500, Olympus) was used to visualize the immunofluorescent staining. Image J was used to immunofluorescence analysis.

\section{Statistical Analysis}

Data were expressed using means \pm standard error of the means (SEMs). We applied student's $t$-test to analyze statistical differences between two groups, and one-way ANOVA for multiple groups. In all cases, $P<0.05$ was considered significant. GraphPad Prism and SPSS (Statistical Product and Service Solutions) were used for creation of graphs and statistical analyses, respectively.

\section{RESULTS}

\section{The Differences Between $\mathrm{GHSR}^{+/+}$and GHSR $^{-/-}$Mice in Food Intake and Blood Glucose}

First, we compared food intake and blood glucose state between $\mathrm{GHSR}^{+/+}$and $\mathrm{GHSR}^{-/-}$mice. In accordance with previous reports (38), the deletion of GHSR attenuated cumulative food intake both in mice fed NCD (Figure 1A) and HFD (Figure 1D). Similarly, consistent with the findings of a prior study (35), the difference of ad libitum blood glucose levels between $\mathrm{GHSR}^{+/+}$ and $\mathrm{GHSR}^{-/-}$mice were not comparable under neither NCD (Figure 1B) or HFD (Figure 1E). However, what we found new was that $24 \mathrm{~h}$-fasted $\mathrm{GHSR}^{-/-}$mice exhibited diminished blood glucose under both NCD and HFD condition. We also found $\mathrm{GHSR}^{-/-}$weighed less than $\mathrm{GHSR}^{+/+}$mice during 8-week breeding (Figure 1C). Additionally, to confirm the effectiveness of HFD, we compared glucose tolerance between NCD and HFD fed mice, and HFD mice showed impaired glucose tolerance as expected (Figure 1F).

\section{Circulating Nesfatin-1 in GHSR $^{+/+}$and GHSR $^{-/-}$Mice}

Since a difference was suggested between $\mathrm{GHSR}^{+/+}$and $\mathrm{GHSR}^{-/-}$mice in terms of food intake and blood glucose, and a previous study demonstrated no altered serum leptin and ghrelin levels due to lack of GHSR (39), we measured circulating levels of nesfatin-1 to see whether the difference between these two types of mice correlated with nesfatin-1. In ad libitum mice, the differences in concentration of serum nesfatin1 in $\mathrm{GHSR}^{+/+}$and $\mathrm{GHSR}^{-/-}$mice did not reach statistical significance, but there was a decreasing tendency in $\mathrm{GHSR}^{-/-}$ mice (Figure 2). Surprisingly, after $12 \mathrm{~h}$ fasting, ELISA showed markedly increased levels of serum nesfatin-1 in $\mathrm{GHSR}^{-/-}$mice compared with levels in mice in the ad libitum group, while nesfatin-1 levels in $\mathrm{GHSR}^{+/+}$mice in the two states showed no differences (Figure 2).

\section{[D-Lys3]-GHRP-6 Attenuated Nesfatin-1's Effects on Blood Glucose and Glucose Tolerance}

We employed the GHSR antagonist [D-Lys3]-GHRP-6 to further probe the correlation of GHSR and nesfatin-1 in food intake and blood glucose levels. No significant alteration in cumulative food intake was found between the vehicle and nesfatin-1 groups (Figure 3A). However, we detected significantly lower blood glucose in mice injected with nesfatin-1 after $3 \mathrm{~h}$, and a declining tendency $(P=0.056)$ was observed after $1 \mathrm{~h}$ (Figure 3C). Nevertheless, no significant altered blood glucose change was observed in $\mathrm{GHSR}^{+/+}$mice injected with [D-Lys3]GHRP-6 compared with that of wild-type mice co-injected with nesfatin-1 and [D-Lys3]-GHRP-6 (Figure 3C). We also investigated the role of chronic administration of nesfatin1 on blood glucose. We monitored blood glucose before and after 11-day chronic administration in four groups of mice (vehicle, nesfatin-1, [D-Lys3]-GHRP-6, and co-injection of nesfatin-1 and [D-Lys3]-GHRP-6). However, no significant difference in blood glucose was observed in mice injected with nesfatin-1 compared with levels in the vehicle group (Figure 3B).

To further investigate the role of GHSR in nesfatin-1's effects on glucose metabolism, we performed OGTT. Nesfatin1 enhanced glucose tolerance in $\mathrm{GHSR}^{+/+}$mice to a greater extent than in the control group, but blood glucose of mice injected with [D-Lys3]-GHRP-6 was similar to that of mice receiving nesfatin-1 and [D-Lys3]-GHRP-6 co-injection during OGTT (Figure 3D), suggesting the function of nesfatin-1 in improving glucose tolerance was at least partially blocked 

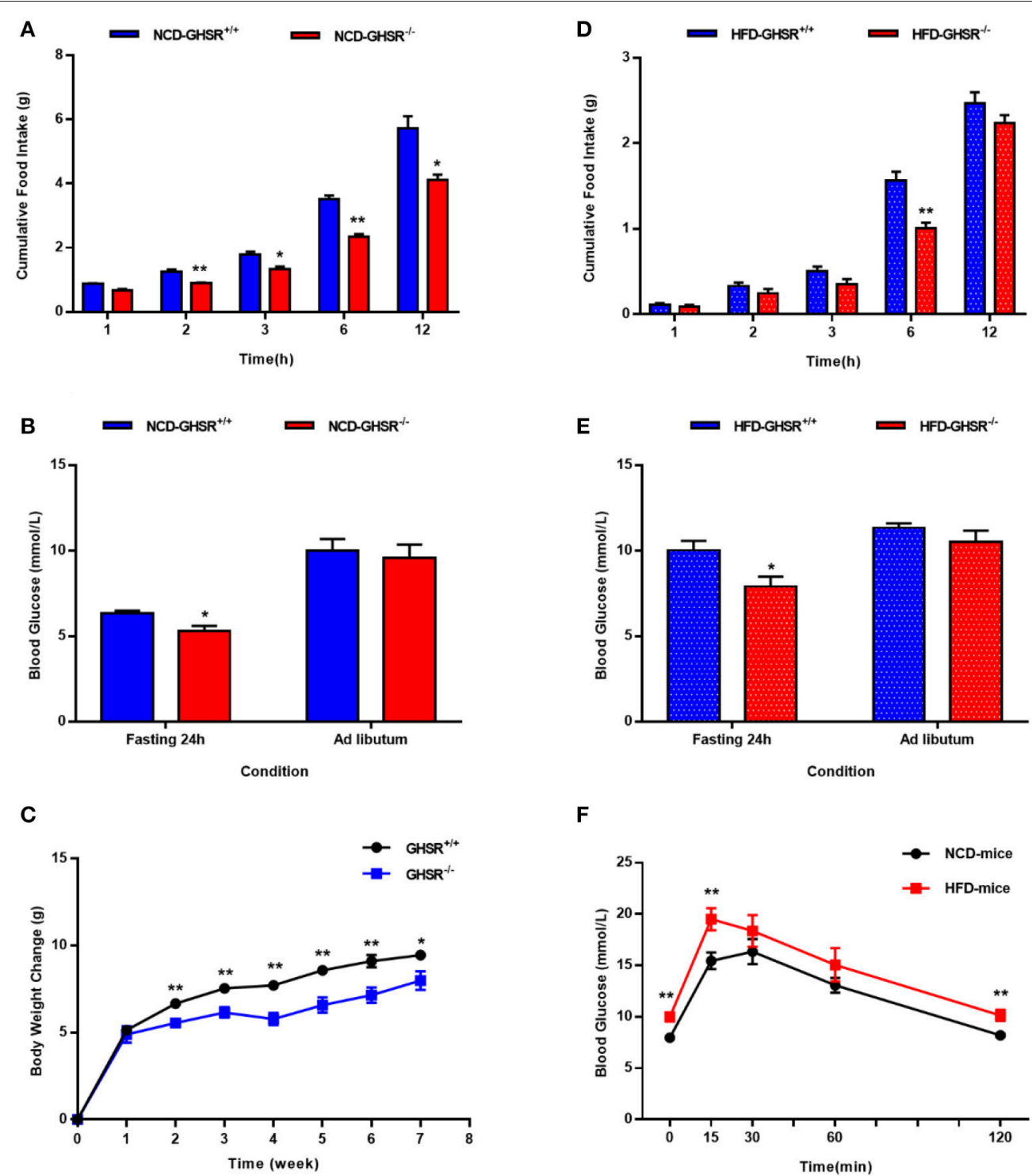

$\mathbf{F}$

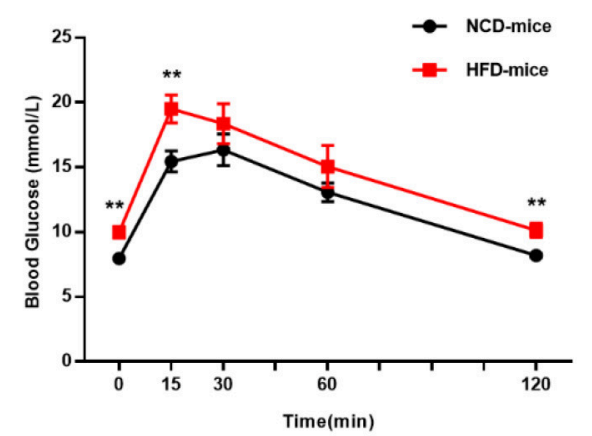

FIGURE 1 | The differences between $\mathrm{GHSR}^{+/+}$and $\mathrm{GHSR}^{-/-}$mice in food intake and blood glucose. Eight-week-old GHSR ${ }^{+/+}$and GHSR ${ }^{-/-}$mice were fed with NCD or HFD for 8 weeks: then mice were inspected respectively. (A,D) Cumulative food intake in GHSR ${ }^{+/+}$and GHSR ${ }^{-/-}$mice fed with (A) NCD or HFD tested after mice fasting for $6 \mathrm{~h}$. (B,E) Blood glucose in $\mathrm{GHSR}^{+/+}$and $\mathrm{GHSR}^{-/-}$mice fed with (B) NCD or (E) HFD under ad libitum or $24 \mathrm{~h}$ fasting conditions. (C) Changes in body weight during 8 weeks of HFD. (F) Oral glucose tolerance tests (OGTT) in mice fed with NCD and HFD. (A,B,D,E) NCD-GHSR ${ }^{+/+}: n=4 ;$ NCD-GHSR ${ }^{-} /-: n$ $=3$; HFD-GHSR ${ }^{+/+}: n=6$; HFD-GHSR ${ }^{-/-}: n=6$. (C) $n=10 /$ group. (F) $n=12 /$ group. Data are expressed as mean \pm SEM. (A-E) ${ }^{\star} P<0.05$, ${ }^{\star \star} P<0.01$ for the effect of $\mathrm{GHSR}^{-/-}$mice vs. GHSR ${ }^{+/+}$mice; (F) ${ }^{\star \star} P<0.01$ for the effect of HFD-mice vs. NCD-mice. Student's $t$-test was applied to analyze the statistical difference.

by GHSR antagonist, which is capable of occupying the GHSR and thus hindering the interaction of nesfatin-1 and GHSR.

\section{Ghrelin Receptor Knockout Blocked the Effects of Nesfatin-1 on Food Intake and Glucose Metabolism}

To move forward another step, GHSR ${ }^{-/}$mice were used in the next experiment. We found that IV injection of nesfatin-1 had no impact on cumulative food intake in
$\mathrm{GHSR}^{-/-}$mice fed NCD during chronic administration (Figure 4A). Consistent with the prior result, GHSR knockout entirely prevented the effect of nesfatin-1 on glucose metabolism (Figures 4B-D). Here we further employed mice fed with HFD. We found that in HFDmice, nesfatin-1 distinctly cut down cumulative food intake, acute and chronic blood glucose, and improved glucose tolerance (Figures 5A-D). There was no difference observed between $\mathrm{GHSR}^{-/-}$mice injected with nesfatin1 and vehicle, just as we observed in NCD-mice (Figures 5E-H). 


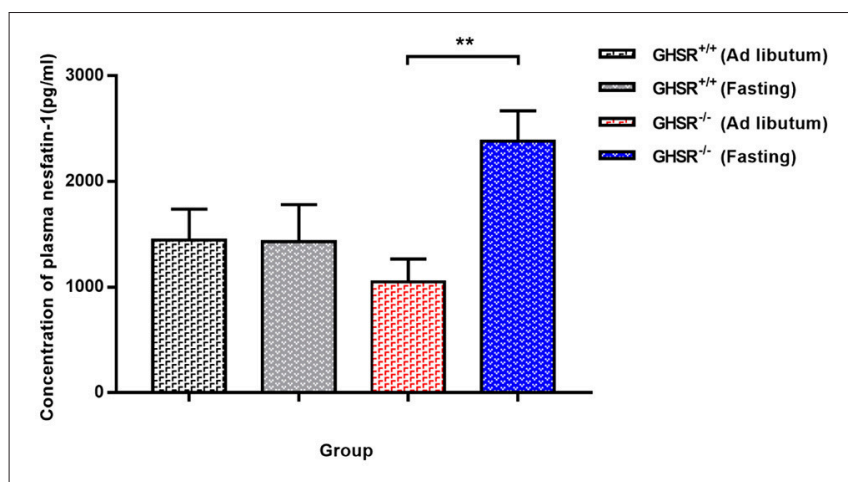

FIGURE 2 | Circulating Nesfatin-1 in $\mathrm{GHSR}^{+/+}$and $\mathrm{GHSR}^{-/-}$Mice. $\mathrm{GHSR}^{+/+}$and $\mathrm{GHSR}^{-/-}$mice were fasted for $12 \mathrm{~h}$ or fed ad libitum. We obtained blood samples from the end of the tail, after which we performed ELISA. Data are expressed as mean $\pm \operatorname{SEM}\left(n=6-7\right.$ /group). ${ }^{\star \star} P<0.01$ for the effect of $\mathrm{GHSR}^{-/-}$mice in fasting condition vs. $\mathrm{GHSR}^{-/-}$mice in ad libitum. $\mathrm{GHSR}^{-/-}$mice in fasting condition vs. GHSR $+/+$mice in fasting condition: $P=0.05$. One-way ANOVA was applied to analyze the statistical difference.

\section{GHSR Mediated the Effect of Nesfatin-1 on AKT Phosphorylation and GLUT4 Membrane Translocation}

We next investigated the possible molecular mechanisms of glucose-regulating effects of nesfatin-1. First, we examined the phosphorylation levels of AKT as a marker of the insulin signaling pathway. Peripheral IV injection of nesfatin1 in $\mathrm{GHSR}^{+/+}$mice under NCD increased the mRNA and phosphorylation levels of AKT in skeletal muscle compared with vehicle (Figures 6A,B), but there were no differences in liver (Figures 7A,B). Nesfatin-1's effects in skeletal muscle were all blocked when co-injected with [D-Lys3]-GHRP-6 (Figures 6A,B), or in $\mathrm{GHSR}^{-/-}$mice (Figures 6D,E).

Next, we examined expression levels of the glucose transporter 4 (GLUT4) after injection of nesfatin-1 in skeletal muscle. We found increased mRNA expression levels of GLUT4 in skeletal muscle (Figure 6A), but the result of protein levels was inconclusive (Figure 6C). Similarly, co-injection with [DLys3]-GHRP-6 (Figure 6A) and deficiency of GHSR (Figure 6D) inhibited the role of nesfatin-1 in improving the expression of GLUT4 mRNA levels in skeletal muscle. And we did not observe any significant change in GLUT4 protein levels in skeletal muscle of GHSR ${ }^{-/-}$mice after nesfatin-1 injection (Figure 6F). We further explored GLUT4 membrane translocation by immunofluorescence. Nesfatin-1 elevated GLUT4 translocation (Figures 6G,H,K), and this effect was not seen in $\mathrm{GHSR}^{-/-}$ mice (Figures 6I-K). These results suggested that nesfatin-1 modulated blood glucose by increasing membrane translocation, but not protein levels of GLUT4.

Because no significant alterations of AKT were observed in the liver of mice fed NCD (Figures 7A-D), we were eager to further investigate the effects in HFD-mice. Interestingly, unlike the results in NCD-mice, nesfatin-1 increased AKT mRNA (Figure 7E) and p-AKT/AKT (Figure 7F) levels in liver of $\mathrm{GHSR}^{+/+}$mice fed with HFD. The effects of nesfatin-1 observed above was not seen in GHSR ${ }^{-/-}$mice (Figures 7G,H).

\section{Nesfatin-1 Inhibited c-fos Expression Induced by Fasting in Arcuate Nucleus}

The next was to investigate the possible mechanisms of interaction between nesfatin-1 and GHSR. We peripherally injected nesfatin-1 in $12 \mathrm{~h}$-fasted mice and measured c-fos expression in ARC by immunofluorescence. It was found that nesfatin-1 markedly suppressed c-fos expression in ARC (Figures 8A,B), suggesting that peripheral nesfatin-1 probably exerted its function at least in part by inhibiting central GHSR signaling.

\section{DISCUSSION}

Although many studies have uncovered the novel function and physiological regulation of nesfatin-1, its receptor has yet to be identified. Nesfatin-1 was found interacting with a $G$ protein-coupled receptor in the rat brain (3), and its peripheral and central localization was described by ${ }^{125}$ I-nesfatin- 1 autoradiography in 2016 (40). A recent article suggested that nesfatin-1 might have anti-inflammatory effects acting through GHSR (41), confirming our findings regarding the relationship between nesfatin-1 and GHSR. Based on the previous findings in this field, we investigated the relationship between GHSR and nesfatin-1. Here we first raised a novel hypothesis that nesfatin-1 regulated satiety and glucose metabolism partly through GHSR, and then verified it experimentally.

In our study, mice were observed to have elevated blood glucose and glucose intolerance during OGTT after 8 weeks feeding of HFD (Figure 1F), which is consistent with previous studies showing impaired glucose homeostasis in the early stage of HFD $(42,43)$. And thus, our HFD model is sufficient to be studied in abnormal glucose metabolism. When we monitored blood glucose of wild-type and $\mathrm{GHSR}^{-/-}$mice before administration, we found an interesting phenomenon: the blood glucose difference between the two types of mice was inconsistent under different energy states (Figures 1B,E). A previous study demonstrated that ghrelin played an important role during fasting by causing the body to switch from glucose utilization to fatty acid oxidation, thus conserving glucose for vital organ functions (44). We thus presumed that the decreased blood glucose caused by fasting triggered ghrelin functioning by promoting this activity via its receptor.

We also investigated plasma levels of nesfatin-1 in the two mice models. A previous study showed significantly reduced circulating nesfatin-1 levels in rats fasted for $24 \mathrm{~h}(45)$. Li et al. confirmed this finding in the stomach of mice (fasted for $24 \mathrm{~h}$ ) (46). By contrast to these studies, in our study, mice under ad libitum and fasting conditions ( $12 \mathrm{~h}$ ) showed no difference in plasma nesfatin-1 levels. The inconsistency may relate to the time of fasting or the different strains. To our surprise, the plasma levels of nesfatin-1 increased significantly after fasting for $12 \mathrm{~h}$ in $\mathrm{GHSR}^{-/-}$mice, suggesting that GHSR may involve in the reaction of nesfatin-1 secretion in various energy states, or the increased circulating nesfatin- 1 was due to loss of function sites (ghrelin receptor) in liver or skeletal muscles, thus become one of the evidence supporting our hypothesis that the glycemic effect of 

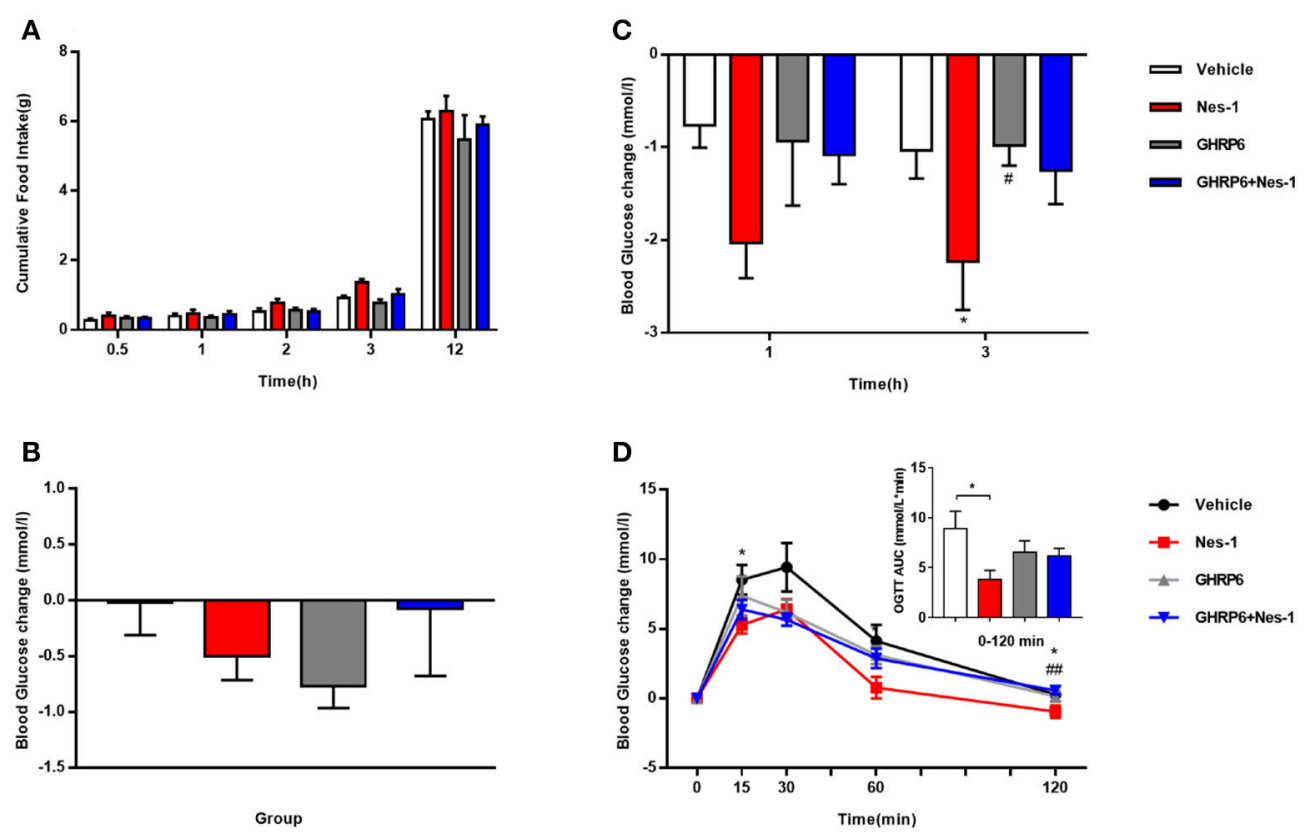

FIGURE 3 | [D-Lys3]-GHRP-6 attenuated nesfatin-1's effects on glucose metabolism. GHSR ${ }^{+/+}$mice fed NCD underwent chronic tail vein administration of vehicle, nesfatin-1 (Nes-1), [D-Lys3]-GHRP-6 (GHRP-6), and [D-Lys3]-GHRP-6+nesfatin-1 (GHRP-6+Nes-1) for 11 days. (A) Food intake and (C) blood glucose changes after one acute injection in mice fasting for $6 \mathrm{~h}$. (B) Blood glucose changes after 11-day chronic injection compared with drug treatment prior. (D) OGTT after 8 days of injection in mice fasting for $16 \mathrm{~h}$. Data are expressed as mean \pm SEM. Vehicle: $n=6$; Nes-1: $n=6$; GHRP-6: $n=6$; GHRP- $6+$ Nes-1: $n=8$. ${ }^{*} P<0.05$ for the effect of nesfatin-1 vs. vehicle; $\# P<0.05$, \#\# $P<0.01$ for the effect of GHRP-6+nesfatin-1 vs. nesfatin-1. One-way ANOVA was applied to analyze the statistical difference.
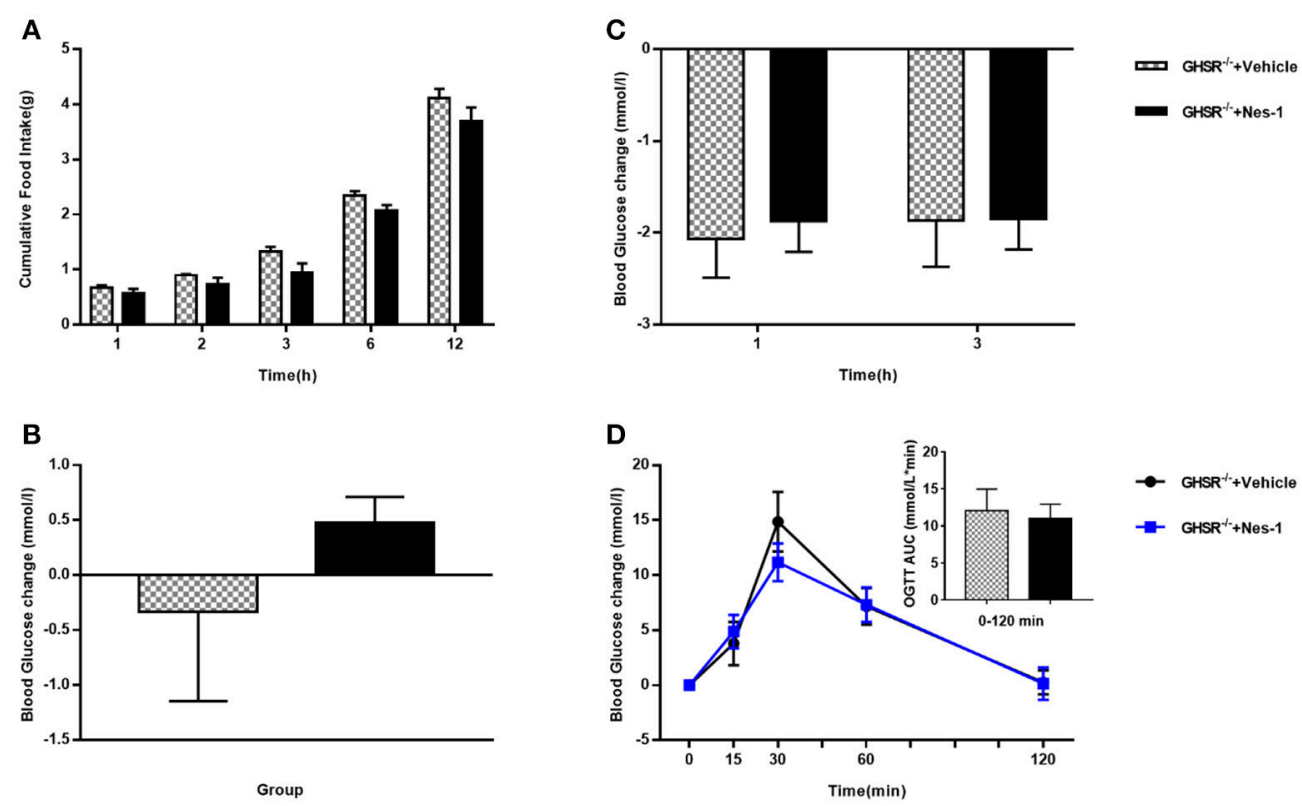

FIGURE 4 | Ghrelin receptor knockout blocked nesfatin-1's effects on glucose metabolism in NCD-fed mice. GHSR ${ }^{-/-}$mice fed NCD underwent chronic tail vein administration of vehicle or nesfatin-1 (Nes-1) for 11 days. (A) Food intake and (C) blood glucose changes after one acute injection in mice fasting for $6 \mathrm{~h}$. (B) Blood glucose changes after 11-day chronic injection compared with drug treatment prior. (D) OGTT after 8 days of injection in mice fasting for $16 \mathrm{~h}$. Data are expressed as mean \pm SEM. GHSR ${ }^{-1-}+$ Vehicle: $n=3$; GHSR ${ }^{-1-}+$ Nes-1: $n=4$. No statistical significance is detected. Student's $t$-test was applied to analyze the statistical difference. 

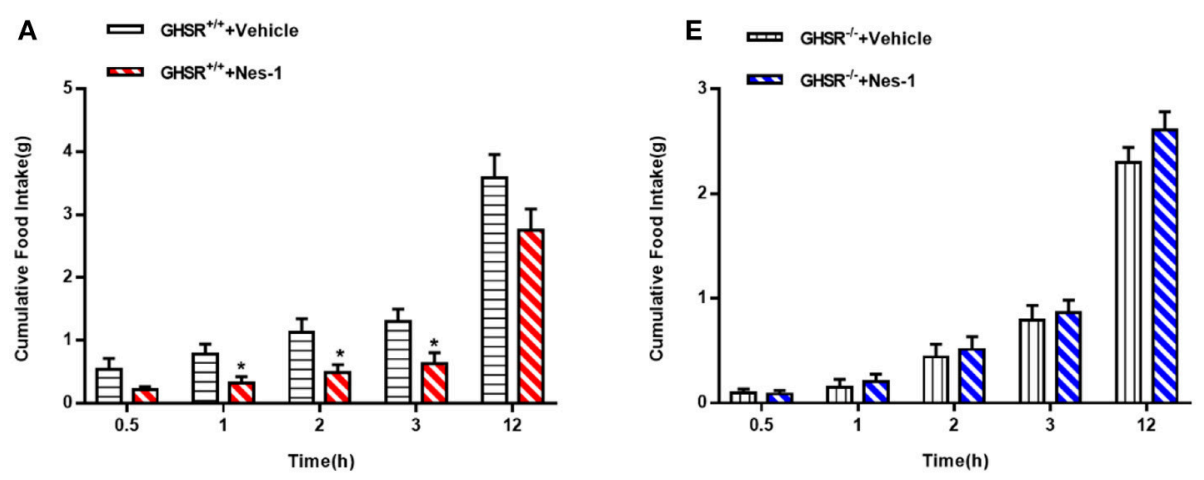

B

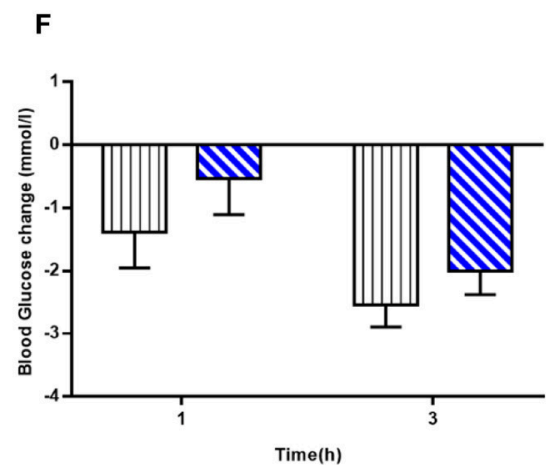

C

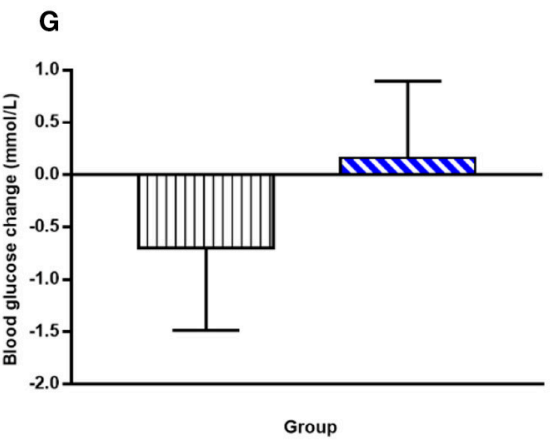

D

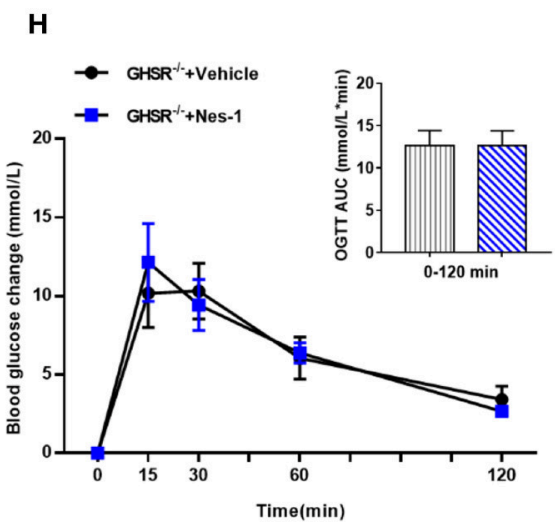

FIGURE 5 | Ghrelin receptor knockout blocked nesfatin-1's effects on food intake and glucose metabolism in HFD-fed mice. GHSR $+/+$ and GHSR ${ }^{-/-}$mice fed HFD underwent chronic tail vein administration of vehicle or nesfatin-1 (Nes-1) for 11 days, respectively. (A,E) Food intake and (B,F) blood glucose changes after one acute injection in two types of mice fasting for 6 h. (C,G) Blood glucose changes after 11-day chronic injection compared with drug treatment prior. (D,H) OGTT after 8 days

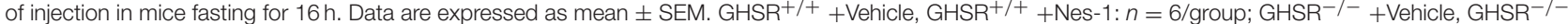

+ Nes-1: $n=5$ /group. ${ }^{*} P<0.05 ;{ }^{* *} P<0.01$ for the effect of nesfatin- 1 vs. vehicle in GHSR ${ }^{+/+}$mice. Student's $t$-test was applied to analyze the statistical difference. 
A

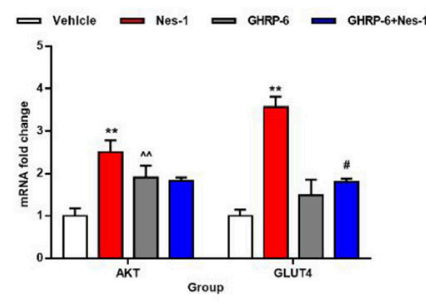

D

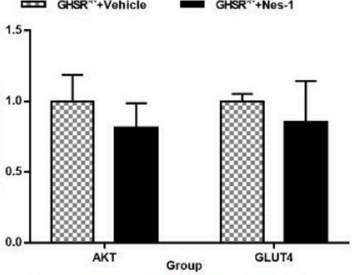

G

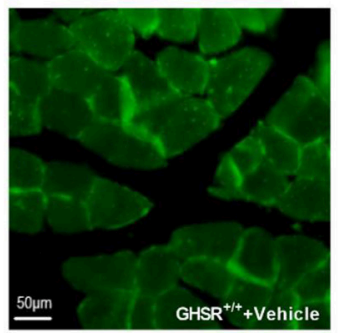

H

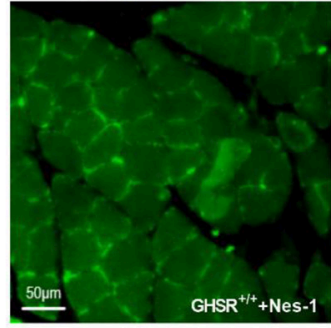

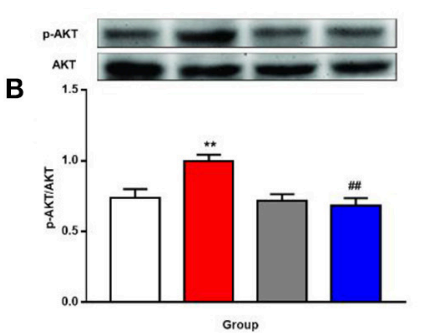

E

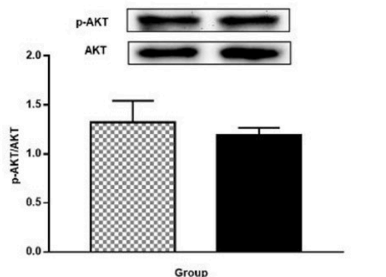

I

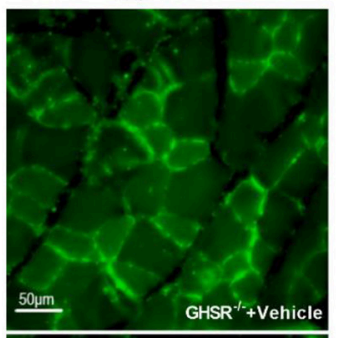

J

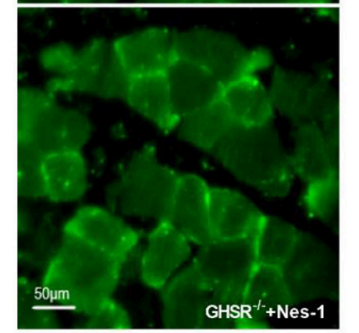

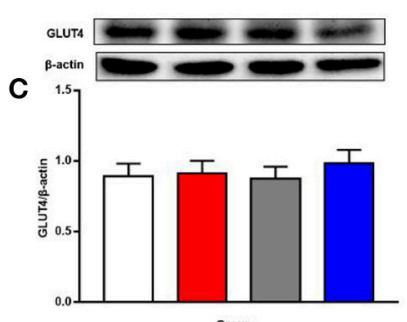

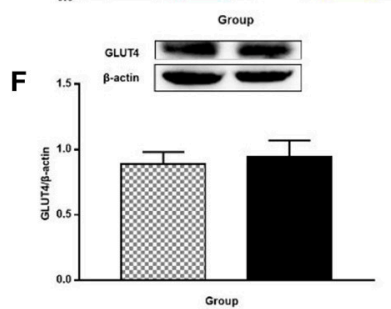

K

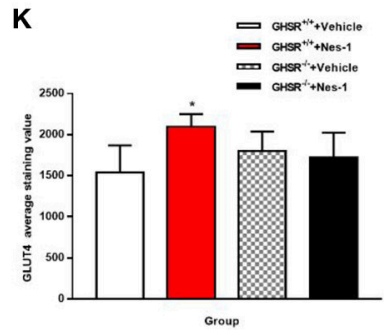

FIGURE 6 | GHSR mediated the effect of nesfatin-1 on AKT phosphorylation and GLUT4 membrane translocation in skeletal muscle. GHSR + /+ mice fed NCD underwent chronic tail vein administration of vehicle, nesfatin-1 (Nes-1), [D-Lys3]-GHRP-6 (GHRP-6), and [D-Lys3]-GHRP-6+nesfatin-1 (GHRP-6+Nes-1) for 12 days. $\mathrm{GHSR}^{-/-}$mice fed NCD underwent chronic tail vein administration of vehicle and nesfatin-1 for 12 days. Insulin (2 IU/kg) was intraperitoneally injected into mice 10 min before mice were sacrificed. (A,D) mRNA expression levels of AKT and GLUT4 detected by RT-PCR in skeletal muscle of (A) GHSR $+/+$ and (D) GHSR ${ }^{-/-}$ mice. (B,E) P-AKT and (C,F) GLUT4 protein levels detected by Western blotting were normalized to total AKT and $\beta$-actin, respectively. (B,E) P-AKT/AKT level in skeletal muscle of (B) GHSR ${ }^{+/+}$and (E) GHSR ${ }^{-/-}$mice. (C,F) GLUT4 level in skeletal muscle of (C) GHSR $^{+/+}$and (F) GHSR ${ }^{-/-}$mice. (G,H) GLUT4 membrane translocation detected by immunofluorescence in skeletal muscle of GHSR ${ }^{+/+}$mice treated with (G) vehicle and (H) nesfatin-1. (I,J) GLUT4 membrane translocation detected by immunofluorescence in skeletal muscle of $\mathrm{GHSR}^{-/-}$mice treated with (I) vehicle and (J) nesfatin-1. (K) GLUT4 average staining value in skeletal muscle of $\mathrm{GHSR}^{+/+}$mice and GHSR ${ }^{-/-}$mice. $n=5 /$ group; (D) GHSR ${ }^{-1-}+$ Vehicle: $n=3, \mathrm{GHSR}^{-/-}+$Nes-1: $n=4$; (E,F) $n=3 / g r o u p ;$ (G-K) $n=3 /$ group. Data are expressed as mean \pm SEM. ${ }^{\star} P<0.05$; ${ }^{\star \star} P<0.01$ for the effect of nesfatin-1 vs. vehicle; $\# P<0.05$, \#\# $P<0.01$ for the effect of GHRP-6+nesfatin-1 vs. nesfatin-1; $\wedge \wedge P<0.01$ for the effect of GHRP-6 vs. vehicle. (A-C,K) One-way ANOVA was applied to analyze the statistical difference for multiple groups.

(D-F) Student's $t$-test was applied to analyze the statistical difference for two groups.

nesfatin-1 requires GHSR. Nevertheless, the concrete mechanism remains uninvestigated.

Previous studies showed conflicting data regarding the peripheral effects of nesfatin-1 on food intake. Shimizu et al. found that intraperitoneal injection of nesfatin-1 displayed an anorexigenic role in mice, but this occurred only when the dose was $>1,000$-fold higher than the dose required by central administration (12). Consistent with what we found, Geobel et al. observed no reduced dark phase food intake in wild-type mice fed NCD induced by peripheral injection of nesfatin-1
(11). The dose of the former (12) was about 75-fold higher than what we used, and the effect of peripheral nesfatin-1 on satiety proved to be dose-independent (12). Thus, we suspect that the dose of nesfatin-1 injected peripherally to mice contributes much to the contradictory results. In addition, in $\mathrm{GHSR}^{+/+}$ mice fed with HFD, intravenous injection of nesfatin-1 reduced dark phase ingestion compared with the control group, a finding similar to what Shimizu et al. found (12). Our observation in mice fed with different diets implies that mice with metabolic disorders were more sensitive to the anorexigenic effect of 


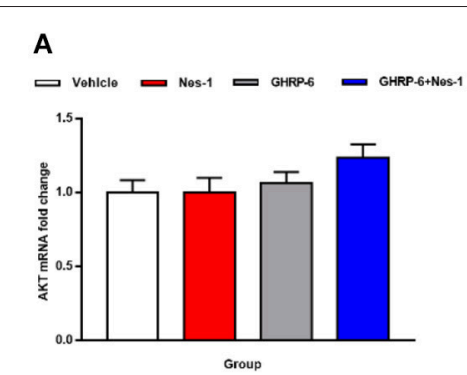

E

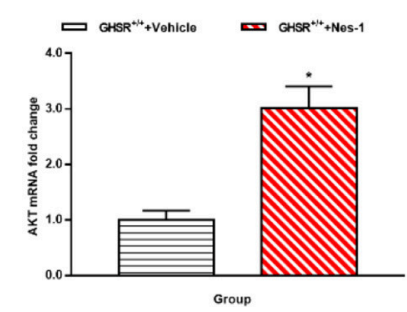

B

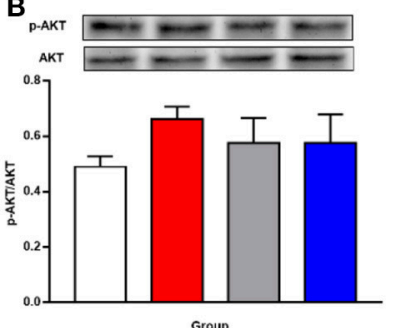

$\mathbf{F}$

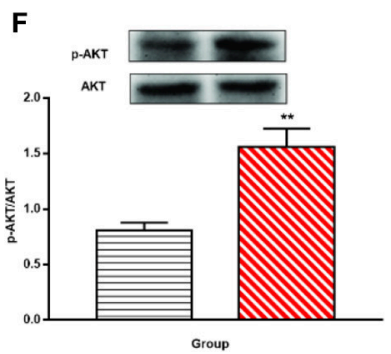

C

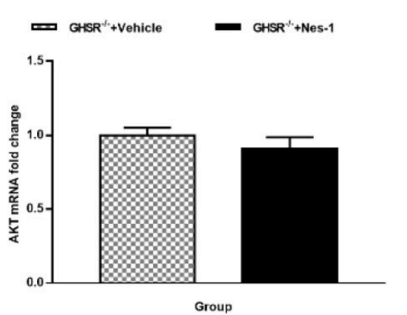

G

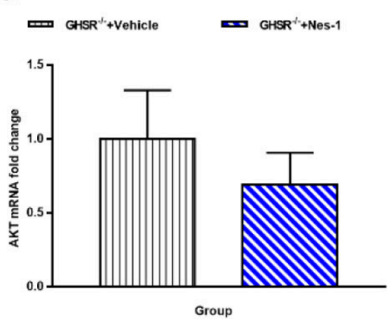

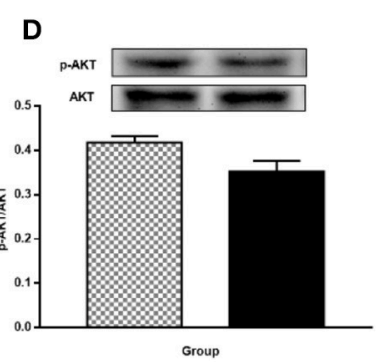

H

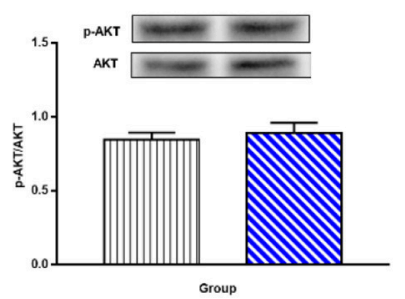

FIGURE 7 | GHSR mediated the effect of nesfatin-1 on AKT phosphorylation in liver of HFD-fed mice. GHSR $+/+$ mice underwent chronic tail vein administration of vehicle, nesfatin-1 (Nes-1), [D-Lys3]-GHRP-6 (GHRP-6) and [D-Lys3]-GHRP-6+nesfatin-1 (GHRP-6+Nes-1) for 12 days. GHSR-/- mice fed underwent chronic tail vein administration of vehicle and nesfatin-1 for 12 days. Insulin (2 IU/ $/ \mathrm{kg}$ ) was intraperitoneally injected into mice $10 \mathrm{~min}$ before mice were sacrificed. (A,C,E,G) mRNA

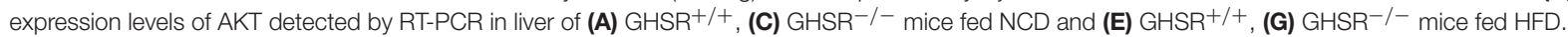

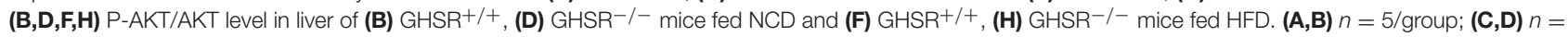
3/group; (E-H) $n=5 /$ group. Data are expressed as mean \pm SEM. ${ }^{*} P<0.05$; ${ }^{* \star} P<0.01$ for the effect of nesfatin-1 vs. vehicle. (A,B) One-way ANOVA was applied to analyze the statistical difference for multiple groups. (C-H) Student's $t$-test was applied to analyze the statistical difference for two groups.

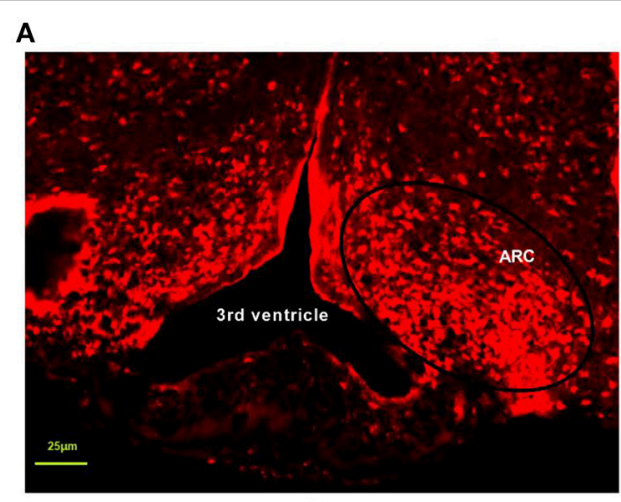

NS

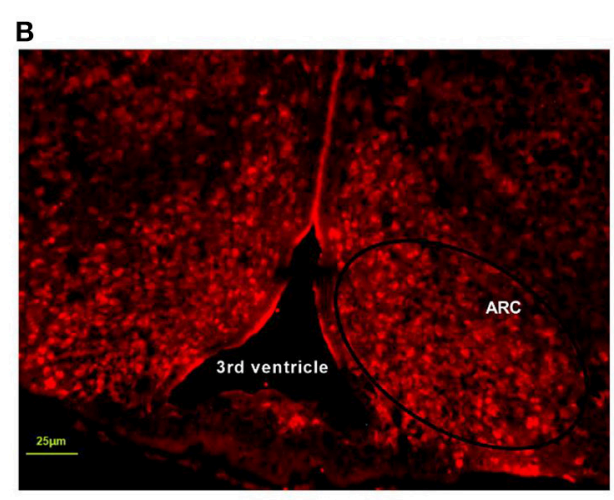

Nesfatin-1

FIGURE 8 | Nesfatin-1 inhibited c-fos expression induced by fasting in arcuate nucleus. GHSR ${ }^{+/+}$mice were treated with tail vein injection of vehicle and nesfatin-1 after $12 \mathrm{~h}$ fasting. (A) C-fos expression in hypothalamic ARC of mice injected with vehicle. (B) C-fos expression in hypothalamic ARC of mice injected with nesfatin-1. $N=3$ group.

nesfatin-1 than were mice in normal energy metabolism states at the same dose of nesfatin-1. More importantly, the effects of nesfatin-1 on food intake were attenuated by [D-Lys3]-GHRP6 in HFD mice, and we confirmed these findings in $\mathrm{GHSR}^{-/-}$ mice. In our previous study, nesfatin-1 stimulated fatty acid oxidation in type 2 diabetes-induced mice (37). To the best of our knowledge, oxidation of fatty acids has always been closely related to regulation of food intake (47). Therefore, there is a possibility that nesfatin-1 exerts its anorexic role in HFD-mice by regulating lipid metabolism that also requires the participation of GHSR.

There were also conflicting results regarding the effects of nesfatin-1 on glucose metabolism. Early investigations showed the positive effects of nesfatin-1 on insulin $(31,48)$. Consistent with our results, some investigators found that peripheral infusion of nesfatin-1 showed a glucose-reducing effect (13, 14). On account of the difference in experimental conditions, Gonzalez et al. found that during the OGTT, blood glucose was 
similar in nesfatin-1 and saline-treated rats (14). Another study suggested that intravenous injection of nesfatin-1 did not affect blood glucose in euglycemic mice (49). Of greater significance from the clinical perspective was that decreased glucose blood glucose was observed in $\mathrm{GHSR}^{+/+}$mice fed with HFD after long-term injection of nesfatin-1, suggesting potential treatment effects of chronic treatment with nesfatin- 1 in patients suffering from related metabolic diseases. Just as we assumed previously, we supposed that the chronic effects of nesfatin-1 on decreasing blood glucose observed in HFD-mice were also related to lipid metabolism. This relationship requires further exploration. Though some conflicts exist, what is more important is that we found that the deficiency of GHSR also completely blocked the glucose-regulating effects of nesfatin-1, further supporting our conjecture.

In addition to these results, we further investigated whether GHSR was involved in the downstream molecular pathway of glucose metabolism regulated by nesfatin-1. A study suggested that AKT was critical for stimulating glucose uptake by skeletal muscle (50), and that AKT phosphorylation induced by insulin resulted in membrane translocation of GLUT4 (51). More decisively, a recent study demonstrated that continuous peripheral administration of nesfatin-1 elevated the activation of AKT as well as GLUT4 expression in an insulin-dependent manner in specific peripheral tissues (13). Therefore, we selected AKT and GLUT4 as the indicators to examine. In agreement with the up-regulated level of p-AKT/AKT in skeletal muscle induced by continuous subcutaneous administration of nesfatin1 found by Li et al. (13), we also found that IV injection of nesfatin-1 increased mRNA and phosphorylation levels of AKT in skeletal muscle. However, $\mathrm{Li}$ et al. found that peripheral nesfatin-1 failed to increase hepatic levels of p-AKT/AKT in HFD-fed mice, only augmenting it in NCD-fed mice, exactly the opposite of our finding. However, Yang et al. found that central nesfatin-1 enhanced hepatic levels of p-AKT/AKT in rats fed HFD, supporting our findings (49) that no significantly altered p-AKT/AKT levels were observed in the livers of mice fed NCD. We conjectured that the response of nesfatin-1 on regulating glucose metabolism mediated by AKT in liver only occurred in situations of metabolic disturbance. Yang et al. also observed markedly improved glucose uptake levels caused by central nesfatin-1 in skeletal muscle (49). The alteration of levels of GLUT4 mRNA and membrane translocation in muscle was congruent with the findings of the abovementioned studies. However, no significant difference as discovered on Western blot between groups with disparate treatments. We attribute this contradiction to the different site of activity (mRNA or protein) modulated by peripheral nesfatin-1, or nesfatin-1 may regulate blood glucose by increasing membrane translocation but not protein levels of GLUT4. We also confirmed previous observations as to the specific-tissue effect of nesfatin-1 on glucose metabolism $(13,49)$. Most of all, both AKT and GLUT4 were similar in $\mathrm{GHSR}^{-/-}$mice regardless of treatment with nesfatin-1 or vehicle, suggesting that GHSR played a crucial role in AKT/GLUT4 passage activated by peripheral injection of nesfatin-1.Our previous hypothesis was that the partial role of nesfatin-1 in satiety and metabolism was indirect mediated by ghrelin secretion, or direct by modulating GHSR activity. Kerbel et al. showed that central administration of nesfatin-1 diminished the expression of ghrelin in goldfish (26). However, we found no alteration of ghrelin levels in $\mathrm{GHSR}^{+/+}$mice after peripheral injection of nesfatin-1 (data not shown). Thus, peripheral nesfatin-1 most likely exerts part of its effect directly through GHSR signaling. GHSR, as a G protein-coupled receptor, was found to function in a highly ligand-independent way, highlighting the potential of GHSR inverse agonists in the field of obesity therapy (25). Nesfatin-1 has almost completely opposite effects to those of ghrelin in terms of energy metabolism, while its function is the same as the identified GHSR inverse agonists $(25,52)$. In addition, peripheral GHSR inverse agonist inhibited fasting-induced c-fos expression in the hypothalamic ARC (52), and we demonstrated that peripheral nesfatin-1 exerted the identical effect on central c-fos expression as an GHSR inverse agonist. Therefore, it is reasonable to regard nesfatin- 1 as an endogenous inverse agonist of the GHSR. Hence, it is possible that nesfatin-1 has an effect on influencing the structure or activity of GHSR. This hypothesis requires verification through further studies.

Here we expanded the existing study regarding the role of peripheral nesfatin-1 on feeding behavior and glucose metabolism. The model of HFD-mice is sufficient for providing potential therapeutic methods in patients with metabolic diseases, especially in patients with glucose metabolic disorders, such as type 2 diabetes mellitus. To the best of our knowledge, no analogical study regarding the relationship between nesfatin1 and GHSR has been published previously. Previous findings implied some correlation between nesfatin-1 and GHSR, and here we confirmed this directly by using GHSR antagonists as well as $\mathrm{GHSR}^{-/-}$mice. Because the receptor for nesfatin1 remains unknown, our study develops a new direction for the investigation of nesfatin-1 receptor. In light of the potential clinical application value in maintenance of glucose metabolic disorders revealed by nesfatin-1, the elucidation of the receptor appears to be particularly consequential. More importantly, GHSR signaling is also an attractive target for the therapy of obesity-related metabolic disease; however a study showed that its ligand, ghrelin, was lower in obese subjects than in a normal group (53). Hence, this limits the effects of the exploration on blockage of ghrelin including inactivation and the use of GHSR antagonists in treatment of metabolic disorders. Therefore, GHSR inverse agonists exhibit unique advantages. Nevertheless, there are remain some disadvantages. The present study was limited to in vivo experiments. There was no exploration of molecular biology, preventing us from directly observing the action of nesfatin-1 on GHSR. Our future studies will compensate for these limitations. According to our results, the application of other metabolic disorder-associated experimental models (e.g., type 1 diabetes and type 2 diabetes) may further advance the relationship between the nesfatin-1 and GHSR.

In conclusion, the main finding of the present study was that GHSR was required for the role of IV administration of nesfatin1 on food intake and glucose metabolism in mice fed both NCD and HFD. GHSR was involved in the AKT/GLUT4 pathway modulated by peripheral nesfatin-1. 


\section{AUTHOR CONTRIBUTIONS}

$\mathrm{X}-\mathrm{TF}$ and $\mathrm{ZT}$ designed the experiments, performed the experiments, researched data, and wrote the manuscript. S-ZL and $\mathrm{TZ}$ designed the experiments, performed the experiments, and researched data. RW, C-SZ, L-XW, and J-HY performed the experiments. J-LL and YZ contributed to discussion of the experiments. JD directed the project, contributed to discussion, reviewed and edited the manuscript. JD as the corresponding

\section{REFERENCES}

1. Oh-I S, Shimizu H, Satoh T, Okada S, Adachi S, Inoue K, et al. Identification of nesfatin-1 as a satiety molecule in the hypothalamus. Nature (2006) 443:70912. doi: $10.1038 /$ nature 05162

2. Zegers D, Beckers S, de Freitas F, Jennes K, Van Camp JK, Mertens IL, et al. Identification of mutations in the NUCB2/nesfatin gene in children with severe obesity. Mol Genet Metab. (2012) 107:729-34. doi: 10.1016/j.ymgme.2012.10.014

3. Brailoiu GC, Dun SL, Brailoiu E, Inan S, Yang J, Chang JK, et al. Nesfatin1: distribution and interaction with a $G$ protein-coupled receptor in the rat brain. Endocrinology (2007) 148:5088-94. doi: 10.1210/en.2007-0701

4. Foo KS, Brismar H, Broberger C. Distribution and neuropeptide coexistence of nucleobindin-2 mRNA/nesfatin-like immunoreactivity in the rat CNS. Neuroscience (2008) 156:563-79. doi: 10.1016/j.neuroscience.2008.07.054

5. Kohno D, Nakata M, Maejima Y, Shimizu H, Sedbazar U, Yoshida N, et al. Nesfatin-1 neurons in paraventricular and supraoptic nuclei of the rat hypothalamus coexpress oxytocin and vasopressin and are activated by refeeding. Endocrinology (2008) 149:1295-301. doi: 10.1210/en.2007-1276

6. Foo KS, Brauner H, Ostenson CG, Broberger C. Nucleobindin-2/nesfatin in the endocrine pancreas: distribution and relationship to glycaemic state. $J$ Endocrinol. (2010) 204:255-63. doi: 10.1677/JOE-09-0254

7. Gonzalez R, Tiwari A, Unniappan S. Pancreatic beta cells colocalize insulin and pronesfatin immunoreactivity in rodents. Biochem Biophys Res Commun. (2009) 381:643-8. doi: 10.1016/j.bbrc.2009.02.104

8. Ramanjaneya M, Chen J, Brown JE, Tripathi G, Hallschmid M, Patel S, et al. Identification of nesfatin-1 in human and murine adipose tissue: a novel depot-specific adipokine with increased levels in obesity. Endocrinology (2010) 151:3169-80. doi: 10.1210/en.2009-1358

9. Stengel A, Goebel M, Yakubov I, Wang L, Witcher D, Coskun T, et al. Identification and characterization of nesfatin-1 immunoreactivity in endocrine cell types of the rat gastric oxyntic mucosa. Endocrinology (2009) 150:232-8. doi: 10.1210/en.2008-0747

10. Angelone T, Filice E, Pasqua T, Amodio N, Galluccio M, Montesanti G, et al. Nesfatin-1 as a novel cardiac peptide: identification, functional characterization, and protection against ischemia/reperfusion injury. Cell Mol Life Sci. (2013) 70:495-509. doi: 10.1007/s00018-012-1138-7

11. Goebel M, Stengel A, Wang L, Tache Y. Central nesfatin-1 reduces the nocturnal food intake in mice by reducing meal size and increasing inter-meal intervals. Peptides (2011) 32:36-43. doi: 10.1016/j.peptides.2010.09.027

12. Shimizu H, Oh IS, Hashimoto K, Nakata M, Yamamoto S, Yoshida $\mathrm{N}$, et al. Peripheral administration of nesfatin-1 reduces food intake in mice: the leptin-independent mechanism. Endocrinology (2009) 150:662-71. doi: 10.1210/en.2008-0598

13. Li Z, Gao L, Tang H, Yin Y, Xiang X, Li Y, et al. Peripheral effects of nesfatin-1 on glucose homeostasis. PLOS ONE (2013) 8:e71513. doi: 10.1371/journal.pone.0071513

14. Su Y, Zhang J, Tang Y, Bi F, Liu JN. The novel function of nesfatin1: anti-hyperglycemia. Biochem Biophys Res Commun. (2010) 391:1039-42. doi: 10.1016/j.bbrc.2009.12.014

15. Kojima M, Hosoda H, Date Y, Nakazato M, Matsuo H, Kangawa K. Ghrelin is a growth-hormone-releasing acylated peptide from stomach. Nature (1999) 402:656-60. doi: 10.1038/45230 author had full access to all the data in the study and had final responsibility for the decision to submit for publication. X-TF, ZT, S-ZL, and TZ contributed equally to this work.

\section{FUNDING}

This work was supported by grants (to JD) from the National Natural Science Foundation of China (No. 31371168 and No. 31872791).

16. Wren AM, Seal LJ, Cohen MA, Brynes AE, Frost GS, Murphy KG, et al. Ghrelin enhances appetite and increases food intake in humans. J Clin Endocrinol Metab. (2001) 86:5992. doi: 10.1210/jcem.86.12.8111

17. Wren AM, Small CJ, Abbott CR, Dhillo WS, Seal LJ, Cohen MA, et al. Ghrelin causes hyperphagia and obesity in rats. Diabetes (2001) 50:2540-7. doi: 10.2337/diabetes.50.11.2540

18. Heijboer AC, van den Hoek AM, Parlevliet ET, Havekes LM, Romijn JA, Pijl $\mathrm{H}$, et al. Ghrelin differentially affects hepatic and peripheral insulin sensitivity in mice. Diabetologia (2006) 49:732-8. doi: 10.1007/s00125-006-0138-2

19. Dezaki K, Sone H, Yada T. Ghrelin is a physiological regulator of insulin release in pancreatic islets and glucose homeostasis. Pharmacol Ther. (2008) 118:239-49. doi: 10.1016/j.pharmthera.2008.02.008

20. Holst B, Schwartz TW. Constitutive ghrelin receptor activity as a signaling set-point in appetite regulation. Trends Pharmacol Sci. (2004) 25:113-7. doi: 10.1016/j.tips.2004.01.010

21. Shiiya T, Nakazato M, Mizuta M, Date $Y$, Mondal MS, Tanaka M, et al. Plasma ghrelin levels in lean and obese humans and the effect of glucose on ghrelin secretion. J Clin Endocrinol Metab. (2002) 87:240-4. doi: $10.1210 /$ jcem.87.1.8129

22. Cummings DE, Purnell JQ, Frayo RS, Schmidova K, Wisse BE, Weigle DS. A preprandial rise in plasma ghrelin levels suggests a role in meal initiation in humans. Diabetes (2001) 50:1714-9. doi: 10.2337/diabetes.50.8.1714

23. Mittelman SD, Klier K, Braun S, Azen C, Geffner ME, Buchanan TA. Obese adolescents show impaired meal responses of the appetiteregulating hormones ghrelin and PYY. Obesity (2010) 18:918-25. doi: 10.1038/oby.2009.499

24. Chacko SK, Haymond MW, Sun Y, Marini JC, Sauer PJ, Ma X, et al. Effect of ghrelin on glucose regulation in mice. Am J Physiol Endocrinol Metab. (2012) 302:E1055-62. doi: 10.1152/ajpendo.00445.2011

25. Holst B, Cygankiewicz A, Jensen TH, Ankersen M, Schwartz TW. High constitutive signaling of the ghrelin receptor-identification of a potent inverse agonist. Mol Endocrinol. (2003) 17:2201-10. doi: 10.1210/me.2003-0069

26. Kerbel B, Unniappan S. Nesfatin-1 suppresses energy intake, co-localises ghrelin in the brain and gut, and alters ghrelin, cholecystokinin and orexin mRNA expression in goldfish. J Neuroendocrinol. (2012) 24:366-77. doi: 10.1111/j.1365-2826.2011.02246.x

27. Stengel A, Goebel M, Wang L, Tache Y. Ghrelin, des-acyl ghrelin and nesfatin1 in gastric X/A-like cells: role as regulators of food intake and body weight. Peptides (2010) 31:357-69. doi: 10.1016/j.peptides.2009.11.019

28. Cameron KO, Bhattacharya SK, Loomis AK. Small molecule ghrelin receptor inverse agonists and antagonists. J Med Chem. (2014) 57:8671-91. doi: $10.1021 /$ jm5003183

29. Kurashina T, Dezaki K, Yoshida M, Sukma Rita R, Ito K, Taguchi M, et al. The beta-cell GHSR and downstream cAMP/TRPM2 signaling account for insulinostatic and glycemic effects of ghrelin. Sci Rep. (2015) 5:14041. doi: 10.1038/srep14041

30. Raghay K, Gallego R, Scoazec JY, Garcia-Caballero T, Morel G. Different ghrelin localisation in adult human and rat endocrine pancreas. Cell Tissue Res. (2013) 352:487-94. doi: 10.1007/s00441-013-1593-y

31. Gonzalez R, Perry RLS, Gao X, Gaidhu MP, Tsushima RG, Ceddia RB, et al. Nutrient responsive nesfatin-1 regulates energy balance and induces glucose-stimulated insulin secretion in rats. Endocrinology (2011) 152:362837. doi: 10.1210/en.2010-1471 
32. Riva M, Nitert MD, Voss U, Sathanoori R, Lindqvist A, Ling C, et al. Nesfatin1 stimulates glucagon and insulin secretion and beta cell NUCB2 is reduced in human type 2 diabetic subjects. Cell Tissue Res. (2011) 346:393-405. doi: 10.1007/s00441-011-1268-5

33. Dezaki K, Hosoda H, Kakei M, Hashiguchi S, Watanabe M, Kangawa K, et al. Endogenous ghrelin in pancreatic islets restricts insulin release by attenuating $\mathrm{Ca} 2+$ signaling in beta-cells: implication in the glycemic control in rodents. Diabetes (2004) 53:3142-51. doi: 10.2337/diabetes.53.12.3142

34. Rankin MM, Kushner JA. Adaptive $\beta$-cell proliferation is severely restricted with advanced age. Diabetes (2009) 58:1365-72. doi: 10.2337/db08-1198

35. Sun Y, Butte NF, Garcia JM, Smith RG. Characterization of adult ghrelin and ghrelin receptor knockout mice under positive and negative energy balance. Endocrinology (2008) 149:843-50. doi: 10.1210/en.2007-0271

36. Liu B, Lu H, Li D, Xiong X, Gao L, Wu Z, et al. Aberrant expression of FBXO2 disrupts glucose homeostasis through ubiquitin-mediated degradation of insulin receptor in obese mice. Diabetes (2017) 66:689-98. doi: $10.2337 / \mathrm{db} 16-1104$

37. Dong J, Xu H, Wang PF, Cai GJ, Song HF, Wang CC, et al. Nesfatin1 stimulates fatty-acid oxidation by activating AMP-activated protein kinase in STZ-induced type 2 diabetic mice. PLoS ONE (2013) 8:e83397. doi: 10.1371/journal.pone.0083397

38. Zigman JM, Nakano Y, Coppari R, Balthasar N, Marcus JN, Lee CE, et al. Mice lacking ghrelin receptors resist the development of diet-induced obesity. J Clin Invest. (2005) 115:3564-72. doi: 10.1172/JCI26002

39. Sun Y, Wang P, Zheng H, Smith RG. Ghrelin stimulation of growth hormone release and appetite is mediated through the growth hormone secretagogue receptor. Proc Natl Acad Sci USA. (2004) 101:4679-84. doi: 10.1073/pnas.0305930101

40. Prinz P, Goebel-Stengel M, Teuffel P, Rose M, Klapp BF, Stengel A. Peripheral and central localization of the nesfatin-1 receptor using autoradiography in rats. Biochem Biophys Res Commun. (2016) 470:521-7. doi: 10.1016/j.bbrc.2016.01.113

41. Ozturk CC, Oktay S, Yuksel M, Akakin D, Yarat A, Kasimay Cakir O. Antiinflammatory effects of nesfatin-1 in rats with acetic acid - induced colitis and underlying mechanisms. J Physiol Pharmacol. (2015) 66:741-50.

42. Mosser RE, Maulis MF, Moulle VS, Dunn JC, Carboneau BA, Arasi K, et al. High-fat diet-induced beta-cell proliferation occurs prior to insulin resistance in C57Bl/6J male mice. Am J Physiol Endocrinol Metab. (2015) 308:E573-82. doi: 10.1152/ajpendo.00460.2014

43. Ahrén B, Pacini G, Ader M, Ni T, Bergman R, Ader M, et al. Insufficient islet compensation to insulin resistance vs. reduced glucose effectiveness in glucose-intolerant mice. Am J Physiol Endocrinol Metab. (2002) 283:E738-44. doi: 10.1152/ajpendo.00199.2002

44. Pinkney J. The role of ghrelin in metabolic regulation. Curr Opin Clin Nutr Metab Care (2014) 17:497-502. doi: 10.1097/MCO.0000000000000101
45. Mortazavi S, Gonzalez R, Ceddia R, Unniappan S. Long-term infusion of nesfatin-1 causes a sustained regulation of whole-body energy homeostasis of male Fischer 344 rats. Front Cell Dev Biol. (2015) 3:22. doi: 10.3389/fcell.2015.00022

46. Li Z, Xu G, Li Y, Zhao J, Mulholland MW, Zhang W. mTOR-dependent modulation of gastric nesfatin-1/NUCB2. Cell Physiol Biochem. (2012) 29:493-500. doi: 10.1159/000338503

47. Leonhardt M, Langhans W. Fatty acid oxidation and control of food intake. Physiol Behav. (2004) 83:645-51. doi: 10.1016/j.physbeh.2004.07.033

48. Gonzalez R, Reingold BK, Gao X, Gaidhu MP, Tsushima RG, Unniappan S. Nesfatin-1 exerts a direct, glucose-dependent insulinotropic action on mouse islet beta- and MIN6 cells. J Endocrinol. (2011) 208:R9-16. doi: 10.1530/JOE-10-0492

49. Yang M, Zhang Z, Wang C, Li K, Li S, Boden G, et al. Nesfatin-1 action in the brain increases insulin sensitivity through Akt/AMPK/TORC2 pathway in diet-induced insulin resistance. Diabetes (2012) 61:1959-68. doi: $10.2337 / \mathrm{db} 11-1755$

50. Sylow L, Kleinert M, Pehmoller C, Prats C, Chiu TT, Klip A, et al. Akt and Racl signaling are jointly required for insulin-stimulated glucose uptake in skeletal muscle and downregulated in insulin resistance. Cell Signal. (2014) 26:323-31. doi: 10.1016/j.cellsig.2013.11.007

51. Hajduch E, Alessi DR, Hemmings BA, Hundal HS. Constitutive activation of protein kinase $\mathrm{B}$ alpha by membrane targeting promotes glucose and system A amino acid transport, protein synthesis, and inactivation of glycogen synthase kinase 3 in L6 muscle cells. Diabetes (1998) 47:1006-13. doi: 10.2337/diabetes.47.7.1006

52. Abegg K, Bernasconi L, Hutter M, Whiting L, Pietra C, Giuliano C, et al Ghrelin receptor inverse agonists as a novel therapeutic approach against obesity-related metabolic disease. Diabetes Obesity Metab. (2017) 19:1740-50. doi: 10.1111/dom.13020

53. Tschop M, Weyer C, Tataranni PA, Devanarayan V, Ravussin E, Heiman ML. Circulating ghrelin levels are decreased in human obesity. Diabetes (2001) 50:707-9. doi: 10.2337/diabetes.50.4.707

Conflict of Interest Statement: The authors declare that the research was conducted in the absence of any commercial or financial relationships that could be construed as a potential conflict of interest.

Copyright (c) 2018 Fan, Tian, Li, Zhai, Liu, Wang, Zhang, Wang, Yuan, Zhou and Dong. This is an open-access article distributed under the terms of the Creative Commons Attribution License (CC BY). The use, distribution or reproduction in other forums is permitted, provided the original author(s) and the copyright owner(s) are credited and that the original publication in this journal is cited, in accordance with accepted academic practice. No use, distribution or reproduction is permitted which does not comply with these terms. 